\title{
A grande guerra do homem branco ${ }^{1}$
}

\author{
The great white man's war
}

La gran guerra del hombre blanco

JerzyMazurek ${ }^{*}$

\section{Resumo}

A Primeira Guerra Mundial (1914-1918) foi o primeiro conflito armado em escala mundial. As razões desse conflito foram as rivalidades entre os impérios da Europa, que na virada do Século XIX para o Século XX se dividiram em dois campos antagônicos. Em um, conhecido como Tríplice Aliança (ou Impérios Centrais), estavam a Alemanha, a Áustria-Hungria e a Itália (mais tarde também a Turquia e a Bulgária). No segundo, a chamada Tríplice Entente ou Aliados, que era constituída pela Grã-Bretanha, França e Rússia. Da Primeira Guerra Mundial participaram 28 países (quatro no lado da Tríplice Aliança e 24 no lado da Entente). Apesar da enormidade das perdas e danos, a guerra não resolveu a maioria dos conflitos, levando à eclosão da Segunda Guerra Mundial 21 anos depois.

Palavras-chave: Bálcãs. Entente. Tríplice Entente. Tríplice Aliança. Revolução Russa. Primeira Guerra Mundial. Conferência de Versalhes.
O conflito mundial dos anos 19141918, chamado atualmente Primeira Guerra Mundial, foi um dos mais destruidores na história da humanidade. Em consequência desse, caíram os velhos impérios e deixou-se de assistir o velho mundo. Dissolveram-se a monarquia austro-húngara, a Alemanha e o Império Otomano. A Áustria se tornou uma república, surgiu a Rússia Soviética, além do que muitos países, entre os quais a Polônia, reconquistaram sua independência. Realizou-se também uma nova divisão das

\footnotetext{
Mestre em História (1991), Mestre em Biblioteconomia e Pesquis Científica (1988). Doutor em História pela Universidade de Szczecin (2006). Redator-chefe da "Gazety Rolniczej". Bolsista do The Marshall Fund(1994) em Washington. Atual vice-diretor do Muzeum Historii Polskiego Ruchu Ludowego (Museu Histórico do Movimento do Povo Polonês), em Varsóvia (desde 1998) e professor no Instituto de Estudos Ibéricos e Ibero-americanos da Universidade de Varsóvia. E-mail: j.mazurek@mhprl.p
}

Recebido em 01/10/2014 - Aprovado em 10/10/2014 http://dx.doi.org/10.5335/hdtv.14n.2.4571 
colônias, e novas fronteiras foram traçadas na Ásia e na África. Na realidade, destruiu-se a "Europa dos reis", mas logo após o encerramento das operações bélicas surgiram duas ideologias totalitárias - o fascismo e o comunismo. No decorrer do conflito, foram mobilizadas 65 milhões de pessoas, das quais pereceram mais de 8,5 milhões, e 21,2 milhões ficaram feridas. Como ocorreu esse cataclismo e será que ele realmente tinha de ter ocorrido?

A resposta à pergunta acima tem de ser afirmativa. Com efeito, as fontes desse conflito encontram-se na ordem política que havia sido instituída quase cem anos antes, no Congresso de Viena. Os quatro países vencedores - Rússia, Prússia, Áustria e Grã-Bretanha - dividiram a Europa entre as suas áreas de influência. O Congresso devia significar a base para a paz eterna entre os seus principais signatários, e um dos seus postulados era o equilíbrio de forças. Graças a isso a Europa não sofreu um conflito maior quase por um século inteiro. Naquele tempo, chamado pelos franceses de belle époque, acreditava-se no progresso, no desenvolvimento e no bem-estar. No entanto, durante esse período de relativa paz manifestaram-se os antigos e eternos antagonismos. A vitória da Prússia e dos estados alemães unidos sobre a França na guerra de 1870-1871 e a seguir a unificação da Alemanha provocaram uma mudança fundamental na Europa. A Alemanha tornou-se o estado mais forte no velho continente e, para preservar essa situação, procurava isolar politicamente a França. Por isso, no dia 7 de outubro de 1879, foi assinada uma aliança com a Áustria-Hungria. O então chanceler do II Reich,
Otto von Bismarck (1815-1898), que temia obsessivamente os contatos russo-franceses, empenhava-se por unir a Rússia a essa aliança. Esses planos foram frustrados pelo conflito balcânico entre a Áustria-Hungria e a Rússia. Quando em 1881 a França ocupou a Tunísia, o "Chanceler de ferro" aproveitou-se da insatisfação da Itália e conseguiu atrair esse país a uma aliança contra a França. Dessa forma, surgiu um dos dois blocos político-militares na Europa, definido como a Tríplice Aliança.

A outra aliança que se formou na Europa foi a Tríplice Entente. Esse pacto se baseava no acordo franco-britânico da entente cordiale, assinado em 1904, e na aliança de Paris com Petersburgo, firmada em 1894. Uma complementação do pacto foi o acordo concluído entre os britânicos e os russos em 1907, no qual foi realizada a divisão das zonas de influência na Pérsia, no Afeganistão e no Tibete. A base da aliança, que se direcionava contra o II Reich, era constituída por três estados: Rússia, França e Grã-Bretanha. Com o tempo, juntaram-se ao acordo os aliados do Império Russo - Sérvia e Romênia, bem como os aliados da Grã-Bretanha - Grécia e Bélgica, que assinaram um pacto militar.

A maioria dos estados de ambos os blocos possuíam antigos e inflamados conflitos territoriais, e não apenas na Europa. A Alemanha - como se argumentava - estava lutando por um "lugar ao sol" e tinha por objetivo a conquista de colônias. A principal direção das ações alemãs tornou-se o continente africano, o que levou a antagonismos, principalmente franco-alemães. $\mathrm{O}$ conflito mais violento foi travado pelo controle do Marrocos - finalmente anexado pela 
França, pelo que Berlim obteve a permissão para ocupar as áreas orientais do Camarões Oriental (por força de um acordo do dia 4 de novembro de 1911). Antes disso, pelas mesmas razões, a Alemanha havia apoiado também os africâners ${ }^{2}$ no conflito com a Grã-Bretanha durante a segunda guerra dos bôeres (1899-1902). Demonstrava uma ambição semelhante à aliada da Alemanha, a Itália, que após a unificação buscava a renovatio Imperii Romani (renovação do Império Romano). As suas pretensões direcionavam-se à Argélia, Líbia e Tunísia, territórios que se encontravam sob o domínio francês ou otomano. No final, em consequência da guerra ítalo-turca, passaram ao domínio da Itália os territórios que constituem a atual Líbia. Nos Bálcãs, por sua vez, existia igualmente a antiga rivalidade russo-austríaca, bem como o antagonismo russo-britânico, que se evidenciou também no Extremo Oriente. As potências europeias, sob a liderança dos Estados Unidos, instituíram a política das chamadas portas abertas na China. Essa política pressupunha a igualdade de todos os países nas relações comerciais com a parte terceira - a China. Inicialmente, essa política foi também apoiada pelo Japão, mas num período posterior a política do País do Sol Nascente tornou-se mais radical. Os japoneses, motivados pelo lema "A Ásia para os japoneses", iniciaram uma guerra com a Rússia, atacando Port Arthur. Antes disso, porém, assinaram com os britânicos uma aliança militar em Portsmouth, que permitia aos russos a utilização do Canal de Suez. Isso teve uma grande influência na derrota da Rússia nessa guerra.

Uma razão dos conflitos e das tensões diplomáticas era também o desigual desenvolvimento econômico das diversas regiões da Europa. A passagem do Século XIX para o Século XX trouxe muitas descobertas técnicas e econômicas. Iam surgindo estabelecimentos de indústria pesada. $\mathrm{O}$ desenvolvimento da infraestrutura ferroviária e da navegação marítima contribuiu para a diminuição dos custos de transporte, o que permitiu o comércio até com as mais distantes regiões do mundo. Surgiam grandes corporações industriais, as quais - lutando por mercados de consumo - realizavam a política dos estados dos quais se originavam. Um testemunho de tal expansão foi a marca fabril made in Germany, a primeira desse tipo no mundo, afixada a partir de 1887 nos produtos exportador pelo II Reich. As desigualdades no desenvolvimento econômico dividiram a Europa entre o rico Ocidente setentrional, liderado pela Grã-Bretanha, Alemanha e França, e o pobre Oriente.

A fim de preservar a sua posição dominante na Europa, a Alemanha realizava também um amplo programa de armamento, cuja culminação ocorreu nos anos 1880-1914. A prioridade do II Reich era a infraestrutura ferroviária, que devia servir ao transporte do exército, bem como a equiparação da frota marítima à britânica. Os ingleses aceitaram o desafio. Sabiam que, se não preservassem o domínio dos mares, não seriam capazes de deter as aspirações alemãs à hegemonia. Por isso, em 1889 a Inglaterra elaborou a doutrina do Two Powers Standard, de acordo com a qual - para assegurar o domínio no mar - o país devia possuir uma frota maior que as duas maiores frotas de outros países unidas. Nesse mesmo tempo, os exércitos terrestres da França e da Alemanha duplicaram o seu 
número em relação ao ano de 1870 . Foi introduzido o serviço militar obrigatório, foram elaborados sistemas de reservas materiais e detalhados planos de ações militares para o caso de um conflito. O desenvolvimento tecnológico e organizacional levou à instituição de estados-maiores com organogramas precisos de mobilização e de ações ofensivas. Para o equipamento das forças terrestres e marítimas foram introduzidos novos tipos de armas, como metralhadoras, artilharia pesada, lança-chamas, aviões, modernos navios de guerra - os dreadnaughts, e também submarinos.

Os historiadores por diversas vezes têm mencionado que várias foram as razões que levaram à eclosão da Primeira Guerra Mundial $^{3}$. No entanto, o motivo principal por que a guerra eclodiu justamente em 1914 foi o conflito nos Bálcãs. A situação geopolítica na península balcânica era popularmente definida como o caldeirão dos Bálcãs. "Quando começa a chuviscar nos Bálcãs, toda a Europa sente arrepios", dizia-se nos salões diplomáticos. O principal problema daquela região da Europa era constituído pela diferenciação étnico-religiosa, bem como pela rivalidade das potências pelas zonas de influência. O conflito dizia respeito à Turquia, Rússia e Áustria-Hungria, apoiada pelo II Reich. Já em 1875 eclodiram levantes de libertação nacional na área da Bósnia e da Herzegóvina, Sérvia e Bulgária - então território da Turquia. Os levantes foram apoiados pela Rússia, que declarou guerra à Turquia. Finalmente o conflito se encerrou no Congresso de Berlim de 1878. Segundo as suas decisões, surgiram os estados independentes da Sérvia, Montenegro e
Romênia. Os austríacos obtiveram o domínio sobre o território da Bósnia e Herzegóvina, que finalmente incorporaram ao seu país em 1908. A escalada seguinte do conflito nos Bálcãs ocorreu durante as chamadas guerras balcânicas, travadas nos anos 1912-19134, que modificaram por completo a imagem da região, tanto no sentido territorial como político. A Turquia deixou de ser uma jogadora a ser levada em conta e tornava-se cada vez mais pró-alemã. Os russos, que perderam uma grande parte das influências no Oriente, concentraram-se no apoio político e ao mesmo tempo no esforço de tornar dela dependente a Sérvia, a qual se sentiu suficientemente forte para aguçar a sua política contra a casa de Habsburgo.

Nessa situação, bastava uma faísca para que o caldeirão balcânico explodisse. Essa faísca surgiu em junho de 1914 em Sarajevo, quando se realizavam manobras do exército austro-húngaro. Os austríacos queriam exibir à Sérvia o seu poderio militar $\mathrm{e}$, consequentemente, exercer influência sobre ela. As manobras deviam ser supervisionadas pelo sucessor do trono, Francisco Ferdinando (n. em 1863). No dia 28 de junho de 1914, um membro da organização nacionalista sérvia Mão Negra, Gavrilo Princip (1894-1918), cometeu um atentado contra Francisco Ferdinando. A Áustria-Hungria, instigada pelo imperador da Alemanha Guilherme II (1859-1941), enviou ao governo sérvio um ultimato extremamente áspero e ofensivo, no qual se exigia, entre outras coisas, que fosse realizada uma investigação sob a estrita supervisão de Viena. Com isso, no entanto, a Sérvia não podia concordar. Rejeitou o ultimato, o que levou ao rompi- 
mento das relações diplomáticas por parte da Áustria-Hungria, que no dia 28 de julho proclamou a guerra contra o governo de Belgrado. Quando a Sérvia se encontrou ameaçada, dois dias depois a Rússia anunciou a sua mobilização. Em resposta, a Alemanha declarou a guerra sucessivamente à Rússia - no dia 1 de agosto e à França - no dia 3 de agosto, e a seguir passou à ofensiva, naquele mesmo dia atacando ainda a Bélgica ${ }^{5}$.

O plano de ataque dos exércitos alemães havia sido elaborado já na segunda metade do Século XIX pelo general Alfred von Schlieffen (1833-1913). Esse plano pressupunha o domínio da França no decorrer de seis semanas a partir da mobilização do exército alemão. Esse objetivo devia ser atingido pela remoção das forças da frente oriental e pelo lançamento de quase todo o exército contra a França. O plano pressupunha uma ampla manobra de flanqueamento pela neutra Bélgica. Quase todo o exército devia passar por esse caminho, deixando apenas pequenas forças de defesa na fronteira com a França, contra as principais forças francesas. Após a passagem pela Bélgica, os exércitos alemães deviam contornar Paris pelo oeste e atacar por trás os exércitos franceses, concentrados na fortalecida fronteira franco-alemã. Essa manobra devia flanquear quase todo o exército francês e levar à sua fácil destruição. Após a vitória sobre o vizinho ocidental mais forte, a Alemanha planejava transferir a maioria das suas forças para a frente oriental e concentrar-se na guerra com a Rússia.

A violação, pelo Império Alemão, do tratado internacional sobre a neutralidade da Bélgica foi a razão imediata da entrada da Grã-Bretanha na guerra contra a Alemanha no dia 3 de agosto de 1914. A Bélgica, que de acordo com Schieffen devia cair no máximo dentro de alguns dias, defendeu-se quase por duas semanas, o que atrasou sensivelmente a marcha dos exércitos para Paris. Enquanto isso, os ingleses puderam tranquilamente enviar os seus destacamentos ao norte da França, a fim de ajudar na defesa da capital, e ainda iniciaram o bloqueio marítimo da Alemanha, fechando as saídas do Mar do Norte. A ofensiva alemã contra Paris, iniciada no dia 18 de agosto, foi detida pelos exércitos franco-britânicos comandados pelo general Joseph Joffre (1852-1931), durante a batalha de vários dias nas margens do Marne (5-9 de setembro de 1914). O plano da "guerra relâmpago" não funcionou, e com isso os alemães não conseguiram eliminar a França da guerra. Após dois meses de encarniçadas lutas, a frente de guerra estabeleceu-se ao longo de uma dupla linha de trincheiras, estendendo-se pela França, desde a Suíça até o Canal da Mancha. Iniciou-se uma longa e exterminadora guerra de posições.

Enquanto isso, no leste, o exército russo - sob o comando do general Aleksandr Samsonov (1859-1914) e do general Paweł von Rennenkampfa (1854-1918) - em setembro de 1914 atacou a Prússia Oriental, o que forçou os alemães a transferir uma parte dos seus exércitos para o leste. A contraofensiva dos alemães, sob o comando do general Paul von Hindenburg (1847-1934) e do general Erich Ludendorf (1865-1937), acabou com a efetiva vitória na batalha de Tannenberg (23-30 de agosto de 1914), e a seguir numa segunda batalha, nos Lagos Mazurianos 
(nos dias 6-15 de setembro de 1914). Os russos foram totalmente desalojados do território da Prússia. A Alemanha decidiu também mudar os seus planos anteriores - primeiramente resolveu dominar a Rússia e somente depois acertar as contas em definitivo com a França. Juntou-se às lutas também a Turquia, cuja frota no dia 29 de outubro de 1914 atacou o litoral da Rússia - tendo sido bombardeadas Odessa e Novorossisk. A ofensiva alemã no leste continuou durante todo o ano de 1915, e os exércitos alemães e austro-húngaros penetraram profundamente na Rússia. A frente de guerra estabeleceu-se na linha Riga-Dniestr.

As operações bélicas continuavam também na frente balcânica. No dia 23 de maio de 1915, juntou-se à guerra a Itália, que em razão do conflito com a Áustria-Hungria sobre o Tirol afastou-se da Tríplice Aliança e colocou-se ao lado da Entente. Em junho, os italianos atacaram os austríacos em Isonzo. A guerra prosseguia também na Sérvia. Após sucessos iniciais dos sérvios, em outubro os exércitos austríacos e alemães começaram aos poucos a dominar o seu país. A entrada na guerra da Bulgária naquele mesmo mês, ao lado dos estados centrais, levou à total repressão da resistência sérvia. No início de 1916, a balança da vitória inclinou-se para o lado dos estados centrais, que obtiveram a hegemonia nos Bálcãs, conquistaram grandes áreas no leste e conquistaram a supremacia numérica, material e moral sobre a Entente. A única falha era a falta de um comando único.

O conflito de 1914-1918 desenrolou-se não apenas em território europeu. Lutas podiam ser observadas também no Oriente
Médio, na África e na Ásia Oriental, embora em escala não tão elevada como na Europa. No primeiro ano das operações de guerra, a Alemanha perdeu, em favor das forças anglo-francesas, o Togo e, em 1916, o Camarões. O Japão, aproveitando-se do conflito na Europa, buscou alcançar uma posição de hegemonia na Ásia. Naquela ocasião ocupou as colônias alemãs na China. Operações bélicas iniciaram-se também no Golfo Pérsico, onde um corpo expedicionário britânico ia avançando ao longo do Tigre em direção a Bagdá. No dia 8 de dezembro de 1917, os ingleses entraram em Jerusalém, onde anunciaram a criação na Palestina de uma sede nacional judaica (a chamada declaração de Balfour).

Enquanto isso, no dia 1 de fevereiro de 1917, a Alemanha proclamou que estava dando início a uma ilimitada guerra submarina, o que significava que a marinha alemã devia afundar, sem aviso prévio, todos os navios, especialmente os mercantes, nas águas que cercavam as Ilhas Britânicas, a França e a Itália. A adoção, pela Alemanha, dessa nova concepção de uso dos submarinos prejudicou muito os interesses americanos, que forneciam mercadorias à Europa. Isso provocou um significativo aumento entre os partidários da faç̧ão pró-guerra, intensificado mais ainda após a interceptação e a decifração de um telegrama do ministro das relações exteriores da Alemanha - Arthur Zimmermann (1964-1940), do qual os Estados Unidos ficaram sabendo a respeito dos planos secretos de uma aliança entre o México e a Alemanha. Não querendo admitir isso, no dia 6 de abril de 1917, declararam guerra à Alemanha. 
Nesse ínterim, importantes mudanças ocorreram nos círculos do poder dos principais participantes do conflito. No dia 21 de novembro de 1916, morreu o imperador austríaco Francisco José I (que exercia o poder desde 1848), e o seu sucessor tornou-se Carlos I (1887-1922), o último imperador austríaco. No dia 10 de dezembro, na Grã-Bretanha, para o cargo de primeiro-ministro foi escolhido David Lloyd George (1863-1945), e no dia 13 de novembro de 1917 o comando do governo da França foi assumido por Georges Clemenceau (1841-1929). Uma revolução popular (segundo o calendário gregoriano - em março) derrubou o tsar Nicolau I e a Rússia tornou-se uma república. Alguns meses mais tarde - em outubro de 1917 - o poder foi assumido pelos bolcheviques, que num decreto do dia 8 de novembro decidiram afastar-se da guerra.

Um importante acontecimento propagandístico, embora não tivesse influenciado muito a situação nas frentes de guerra, foi a proclamação, no dia 1 de agosto de 1917, de uma nota de paz pelo papa Bento XV. O plano do chefe da Igreja postulava que os exércitos alemães se afastassem da França e devolvessem a independência à Bélgica. Em troca disso, o Reich receberia de volta as colônias alemãs tomadas. A respeito do destino da Alsácia, da Lotaríngia e do Tirol deviam decidir os habitantes dessas áreas. Era preciso também cuidar do destino da Polônia, da Armênia e dos estados balcânicos. O papa conclamava também ao desarmamento geral, à liberdade de navegação e à renúncia a reparações de guerra. $\mathrm{O}$ fato de que o programa pontifício foi rejeitado confirmou incontestavelmente que a paz só era possível entre vencedores e vencidos.
A fim de poder utilizar as suas forças armadas para a defesa das conquistas da revolução, as autoridades da Rússia buscavam, a todo custo, o término da guerra. Interessada por tal solução estava também a Alemanha - porquanto estava travando uma guerra em duas frentes. Por isso, buscava o fechamento da frente oriental e, a seguir, o direcionamento de todo o esforço militar para a frente ocidental. $O$ tratado entre Berlim e Moscou, assinado no dia 3 de março de 1918 em Brest, decidiu o afastamento da Rússia da guerra e o rompimento da aliança com a Entente. As autoridades da Rússia soviética concordaram, além disso, que o exército alemão ocupasse as áreas a leste da linha fronteiriça estabelecida pelo tratado, o que significava que a Rússia perderia as áreas da atual Polônia, Lituânia, Letônia, Estônia, Bielorrúsia e Finlândia.

Esse tratado teve um enorme significado para a Alemanha, porque permitiu transferir para o oeste 44 divisões do exército, o que era tanto mais importante porque na primavera se havia iniciado a grande ofensiva dos estados aliados na frente ocidental. Tornou-se comandante-chefe o marechal francês Ferdinand Foche (18511929). A contraofensiva decisiva ocorreu no dia 18 de julho nas margens do Marne, e os exércitos alemães foram forçados à retirada. Alguns dias depois, na batalha de Amiens (8-13 de agosto), a Alemanha foi derrotada. Devido à extensão das perdas, o dia 8 de agosto foi chamado pelo comandante das forças alemãs, general Ludendorf, de "Dia negro do exército alemão". Também os aliados da Alemanha não alcançavam sucessos. No dia 29 de setembro, numa batalha con- 
tra os exércitos reunidos franco-sérvios, foi derrotada a Bulgária. No dia 24 de outubro foi também quebrada a resistência austro-húngara em Vittorio Veneto, o que levou à derrota total das forças dos estados centrais na frente italiana.

A derrota dos estados centrais foi decidida não tanto pelos insucessos nas frentes de guerra quanto pelos movimentos revolucionários e nacionalistas no interior dos seus estados. Esses movimentos - como sabemos - ocorreram principalmente no interior da monarquia austro-húngara. A fim da existência do império austríaco devia servir à satisfação das aspirações nacionais. No dia 16 de outubro, o imperador Carlos I anunciou o surgimento da monarquia federativa da casa de Habsburgo. Esse passo estava atrasado em anos inteiros, por isso, não podia produzir os resultados esperados. No dia 28 de outubro, foi proclamada em Praga a independente República da Checoslováquia, e no dia seguinte foi proclamada em Zagreb a criação do estado unificado dos eslovenos, croatas e sérvios. Em Viena, no dia 11 de novembro, foi derrubada a monarquia de Carlos I, e no dia seguinte a Áustria foi proclamada uma república. Alguns dias depois, no dia 16 de novembro, também a Hungria tornou-se uma república. Com isso, deixou de existir definitivamente a secular união que ligava ambos os países.

De maneira um pouco diferente transcorreram os acontecimentos na própria Alemanha. As derrotas na frente de guerra e o longo bloqueio econômico promovido pelos estados da Entente ocasionaram enormes dificuldades econômicas. Nas cidades, eram comuns nas ruas demonstrações pró-comu- nistas. Os operários exigiam a abdicação de Guilherme II, a quem responsabilizavam por toda a guerra. O imperador abdicou somente no dia 9 de novembro, quando a derrota da Alemanha já era certa. Ele viajou para fora da Alemanha, que de fato se tornou uma república, mas a respeito do regime do país devia decidir a futura Assembleia Nacional. No dia 11 de novembro, o governo, composto na sua maioria de social-democratas, assinou o armistício. Muitos alemães acreditavam mais tarde num "golpe pelas costas", que teria decidido a derrota do Reich. Esse golpe teria sido desferido por "inimigos internos", ou seja, pela esquerda alemã. Finalmente, graças a um entendimento entre Fiedrich Ebert (1871-1925) - o último chanceler do Império Alemão (9-11 de novembro) e a seguir primeiro presidente da Alemanha (República de Weimar) e o comando do exército alemão, tornou-se possível a introdução da concepção republicana e a supressão dos distúrbios armados, provocados pela radical União Spartacus, sob o comando de Rosa Luxemburgo (1871-1919) e Karl Liebknecht (1871-1919).

O ano de 1918 encerra definitivamente as lutas da guerra. No dia 29 de setembro, capitula a Bulgária, no dia 30 de outubro cai a Turquia, no dia 3 de novembro a Áustria-Hungria, e no dia 11 de novembro, na floresta de Compiègne, a Alemanha assina o armistício com os estados da Entente. Com isso, a Primeira Guerra Mundial chegou ao fim. O tratado de paz principal que encerrou a Primeira Guerra Mundial foi assinado no dia 28 de junho de 1919 em Versailles - no lugar onde, em 1871, a Alemanha havia proclamado o surgimento do II Reich. Por for- 
ça desse tratado, a Alemanha perdeu cerca de 70,5 mil km² do seu território (habitado por cerca de 6,5 milhões de pessoas) em favor da França, da Bélgica, da Polônia e da Checoslováquia. As colônias alemãs foram divididas entre os vencedores e transferidas à proteção da recém-criada Liga das Nações, que devia solucionar os conflitos mundiais por via pacífica. A Alemanha foi reconhecida como culpada pela eclosão da guerra. O exército alemão (o chamado Reischwehr) podia, a partir de então, contar não mais que 100 mil soldados, que deviam ser exclusivamente voluntários. Foi-lhe proibida a posse de armamento blindado, artilharia pesada, aviação e navios de guerra, bem como submarinos. À Alemanha foi imposta a obrigação de pagar (até 1951) indenizações de guerra na importância de 132 bilhões de marcos em ouro.

\section{Abstract}

The World War I (1914-1918) was the first armed conflict on a worldwide scale. The reason of this conflict was the rivalry between the European empires, which on the turning from the $19^{\text {th }}$ to the $20^{\text {th }}$ century divided in two opposite fields. In one of them, known as the Triple Alliance (or the Central Empires), were Germany, Austria-Hungary and Italy (later also Turkey and Bulgaria). The second, the so called Triple Entente or the Allies, was formed by Great Britain, France and Russia. Twenty eight countries participated in the World War I (four on the side of the Triple Alliance and 24 on the side of the Entente). Notwithstanding the enormity of the losses and damages, the war did not solve the majority of the conflicts and led to the outbreak of the World War II 21 years later.

Keywords: Balkan, Entente, Triple Entente, Triple Alliance, Russian Revolution, World War I, Versailles Conference

\section{Resumen}

La Primera Guerra Mundial (1914-1918) fue el primer conflicto armado en todo el mundo. Las razones de este conflicto fue la rivalidad entre los imperios de Europa, en el cambio del siglo XIX al siglo XX dividido en dos bandos en guerra. En una, conocida como la Triple Alianza (o las Potencias Centrales), fueron Alemania, Austria-Hungría e Italia (más tarde también Turquía y Bulgaria). En la segunda, llamada la Entente o aliados, que fue formado por Gran Bretaña, Francia y Rusia. Guerra Mundial de 28 países participantes (4 en el lado de la Triple Alianza y 24 en el lado de la Entente). A pesar de la enormidad de la pérdida y el daño, la guerra no resolvió la mayoría de los conflictos, lo que lleva al estallido de la Segunda Guerra Mundial 21 años después.

Palabras clave: Balcanes, Entente, Triple Entente, Triple Alianza, Revolución Rusa, Primera Guerra Mundial, Conferencia de Versalles. 


\section{Notas}

O título é uma referência ao ciclo de obras do romancista alemão Arnold Zweig (1887-1968), intitulado A grande guerra dos homens brancos (volumes 1-6, 1927-1954). As experiências adquiridas durante a Primeira Guerra Mundial fizeram com que as obras de Zweig tivessem um nítido colorido pacifista. Nelas, são submetidas a uma análise a política da guerra e as mudanças que ocorrem na psique dos heróis sob a influência da guerra.

2 Africâners - habitantes brancos da República Sul-Africana e da Namíbia, vivendo igualmente na diáspora em muitos países do mundo. Utilizam-se da língua africâner (ou africana) e professam o calvinismo. São descendentes dos colonos holandeses, alemães e franceses que vinham à Colônia do Cabo nos anos 1652-1795. No passado, denominados bôeres (literalmente camponeses, em língua holandesa).

3 James JOLL; Gordon MARTEL. Przyczyny pierwszej wojny światowej. Warszawa: Książka i Wiedza, 2008.

4 Egidio IVETIC. Le guerre balcaniche. Bologna: Il Mulino, 2006; Jacob Gould SCHURMAN. The Balkan Wars, 1912 to 1913. Kessinger Publishing, 2004.

5 Nesse mesmo dia o governo Italiano anunciou a sua neutralidade. Explicou a sua posiçao dizendo que a Austro-Hungria atacou a Servia contra as decisões dos aliados antes de consultas previas. Por causa disso, a Itália considerou-se livre de obrigaçoes diante dos aliados.

\section{Referências}

BECKETT, Ian F. W. The Great War 1914-1918. 2. ed. Harlow: Pearson Education Limited, 2007.

CHICKERING, Roger. Imperial Germany and the Great War, 1914-1918. Cambridge: Cambridge University Press, 2004.

FERRO, Marc. A Grande Guerra - 1914-1918. Lisboa: Edições 70, 2008.

FROMKIN, David. O último verão europeu: Quem começou a grande guerra de 1914? Rio de Janeiro: Objetiva, 2005.

GILBERT, Martin. First World War. London: HarperCollins 1994.
JOLL, James; MARTEL, Gordon. Przyczyny pierwszej wojny światowej. Warszawa: Książka i Wiedza, 2008.

LIDDELL, Hart; HENRY, Basil. History of the First World War. London: Weidenfeld Nicolson, 1970.

PADFIELD, Peter. The Great Naval Race: The Anglo-German Naval Rivalry, 1900-1914. Edinburgh: Birlinn, 2005.

PAJEWSKI, Janusz. Pierwsza wojna światowa 1914-1918. Warszawa: PWN, 2004.

RICH, Norman. Friedrich von Holstein, Politics and Diplomacy in the Era of Bismarck and Wilhelm II, v. 1. London: Cambridge University Press, 1965.

PÉTAIN, Philippe. La bataille de Verdun. Verdun: Fremont [1931).

TRZECIAKOWSKI, Lech. Otto von Bismarck. Wrocław: Ossolineum, 2009.

TUCHAMAN, Barbara Wetheim. Zimmermann Telegram, 2. ed. New York: Macmillan, 1966. 